\title{
Molecular basis for defining the pineal gland and pinealocytes as targets for tumor necrosis factor
}

\section{Claudia Emanuele Carvalho-Sousa ${ }^{1}$, Sanseray da Silveira Cruz-Machado ${ }^{1}$, Eduardo Koji Tamura ${ }^{1}$, Pedro A. C. M. Fernandes' ${ }^{1}$, Luciana Pinato ${ }^{2}$, Sandra M. Muxel' ${ }^{1}$, Erika Cecon ${ }^{1}$ and Regina P. Markus ${ }^{1 *}$}

1 Laboratory of Chronopharmacology, Department of Physiology, Institute of Biosciences, Universidade de São Paulo, São Paulo, Brazil

${ }^{2}$ Department of Speech, Language and Hearing Therapy, Universidade Estadual Paulista, Marilia, Brazil

\section{Edited by:}

Steven M. Hill, Tulane University

School of Medicine, USA

Reviewed by:

Roman L. Bogorad, Massachusetts Institute of Technology, USA

Massimiliano Beltramo, Institut

National de la Recherche

Agronomique, France

\section{*Correspondence:}

Regina P. Markus, Laboratory of Chronopharmacology, Institute of Bioscience, Universidade de São Paulo, Rua do Matão, Travessa 14, 05508-900 São Paulo, Brazil. e-mail: rpmarkus@usp.br
The pineal gland, the gland that translates darkness into an endocrine signal by releasing melatonin at night, is now considered a key player in the mounting of an innate immune response. Tumor necrosis factor (TNF), the first pro-inflammatory cytokine to be released by an inflammatory response, suppresses the translation of the key enzyme of melatonin synthesis (arylalkylamine- $N$-acetyltransferase, Aanat). Here, we show that TNF receptors of the subtype 1 (TNF-R1) are expressed by astrocytes, microglia, and pinealocytes. We also show that the TNF signaling reduces the level of inhibitory nuclear factor kappa B protein subtype A (NFKBIA), leading to the nuclear translocation of two NFKB dimers, p50/p50, and p50/RelA. The lack of a transactivating domain in the p50/p50 dimer suggests that this dimer is responsible for the repression of Aanat transcription. Meanwhile, p50/RelA promotes the expression of inducible nitric oxide synthase (iNOS) and the production of nitric oxide, which inhibits adrenergically induced melatonin production. Together, these data provide a mechanistic basis for considering pinealocytes a target of TNF and reinforce the idea that the suppression of pineal melatonin is one of the mechanisms involved in mounting an innate immune response.

Keywords: pineal gland, immune-pineal axis, melatonin, tumor necrosis factor, nuclear factor kappa B

\section{INTRODUCTION}

The pineal gland is considered the endocrine component of the circadian timing system because it transduces light/dark cycle information into the nocturnal melatonin surge. Melatonin, a highly conserved molecule, acts as an antioxidant in primitive taxa, while in mammals, in addition to its protective effect, it exerts chronobiotic functions (Hardeland and Fuhrberg, 1996; Tan et al., 2010). During the past two decades, several groups have shown the regulatory role of melatonin in the defense response (Lissoni et al., 1994; Nelson et al., 1997; Maestroni, 1998; Guerrero and Reiter, 2002). In addition, the synthesis of melatonin by extra-pineal tissues that are related to defense responses, such as activated polymorpho- and mono-nuclear cells in the blood (Carrillo-Vico et al., 2004), in the peritoneum (Martins et al., 2004), and in the colostrum (Pontes et al., 2006), has been clearly shown. Melatonin's effects include inhibition of nuclear factor kappa B (NFKB), a key transcription factor mediating the mounting of the inflammatory response (Gilad et al., 1998; Beni et al., 2003; Huang et al., 2008; Li et al., 2009; Tamura et al., 2009). Therefore, melatonin is now considered to play an important role in the modulation of inflammatory responses.

More recently, the mounting of inflammatory responses were shown to involve the suppression of the nocturnal melatonin surge (Tamura et al., 2010), reinforcing a putative bidirectional communication between the pineal gland, and the immune system (Skwarlo-Sonta et al., 2003; Markus et al., 2007). However, it remains unknown whether the pineal gland is able to respond to inflammatory mediators or whether it contains the receptors and the downstream mechanism(s) that mediate the pro-inflammatory agent-induced suppression of the nocturnal melatonin surge.

In the rat pineal gland, the nuclear translocation of NFKB presents a daily rhythm (Cecon et al., 2010). At the light/dark transition, there is an abrupt reduction of nuclear NFKB content, which remains low until the next light phase, at which point the nuclear level of NFKB rises continuously until the next light/dark transition. This cycle is regulated on a circadian basis by the internal clock; in animals kept in constant darkness, the reduction in nuclear NFKB content occurs at the subjective day/night transition.

The inducible regulation of gene transcription is a central element in the defense of multicellular organisms against environmental, mechanical, chemical, and microbiological stresses. During resting conditions, NFKB inhibitory protein (NFKBI) binds to NFKB dimers, impairing their nuclear translocation (O'Neill and Kaltschmidt, 1997). Activation of membrane receptors leads to NFKBI phosphorylation and ubiquitination, and its subsequent proteasomal degradation. Free NFKB dimers translocate to the nucleus, bind to the kappa B element of gene promoters and induce or repress the transcription of target genes. The five different subunits of NFKB express REL homology domains, which are responsible for binding to the DNA kappa $\mathrm{B}$ element. These subunits may or may not contain a transactivating domain (TAD), which is essential for inducing promoter activation. The subunits 
p50 and p52 have no TAD, whereas RelA, RelB, and c-Rel express the TAD (Ghosh and Hayden, 2008; O'Dea and Hoffmann, 2009).

Lipopolysaccharide (LPS), a pathogen-associated molecular pattern, suppresses the synthesis of melatonin and induces TNF production in the rat pineal gland by activating toll-like receptor 4 (TLR4), which triggers the nuclear translocation of NFKB (da Silveira Cruz-Machado et al., 2010). Moreover, TNF transiently inhibits the noradrenaline-induced transcription of the arylalkylamine- $N$-acetyltransferase gene (Aanat), which is the enzyme that converts serotonin to $N$-acetylserotonin, the immediate precursor of melatonin (Fernandes et al., 2006). In this study, we aimed to identify the downstream pathway that mediates TNFinduced melatonin suppression in the rat pinealocyte. The present paper shows the cellular distribution of TNF receptors, the nuclear translocation of NFKB dimers induced by TNF in pinealocytes and the functional expression of this pathway.

\section{MATERIALS AND METHODS \\ ANIMALS}

Prepubertal female Wistar rats were kept under a 12:12 h light/dark cycle (lights on at 07h30, named zeitgeber time zero - ZT0) with water and food provided ad libitum. The animals were killed by decapitation between ZT9 and ZT10. All experiments were carried out in compliance with the ethical standards of our institution (Ethics Committee of the Institute of Bioscience of the University of São Paulo; license 081/2008) and the recommendations of the National Council on Experimental Animal Control (CONCEA).

\section{DRUGS AND REAGENTS}

2,5-Diphenyl-2H-tetrazolium bromide (MTT), 4-(2-hydroxyethyl)1-piperazineethanesulfonic acid (HEPES), BGJb medium, bovine albumin fraction $\mathrm{V}$, bovine serum albumin fraction $\mathrm{V}$ (BSA), glycerol, dithiothreitol (DTT), methylenebisacrylamide, penicillin/streptomycin, pyrrolidine dithiocarbamate (PDTC), tris(hydroxymethyl)aminomethane hydrochloride (Tris- $\mathrm{HCl}$ ), trypsin, trypsin inhibitor, and TNF, were purchased from SIGMA (St. Louis, MO, USA). Ascorbic acid and ethylenediamine tetraacetic acid (EDTA) were acquired from Merck (Rio de Janeiro, Brazil). 4-Amino-5-methylamino-2',6-diamidino-2phenylindole (DAPI), $7^{\prime}$-difluorofluorescein diacetate (DAF-FM DA), Dulbecco's Modified Eagle Medium (DMEM), fetal bovine serum, and phenylmethylsulfonyl fluoride (PMSF) were obtained from Invitrogen Life Technologies (Carlsbad, CA, USA). Acrylamide was obtained from Bio-Rad Laboratories (Richmond, CA, USA). Poly (dI-dC) and $\left[\gamma-{ }^{32} \mathrm{P}\right]-A T P$ were purchased from GE Healthcare (Chalfont St Giles, Buckinghamshire, UK). $1400 \mathrm{~W}$ and NP-40 were obtained from Calbiochem (Darmstadt, Germany).

\section{ORGAN CULTURE}

The pineal gland was cultured according to Ferreira et al. (1994). Briefly, the glands were cultivated for $48 \mathrm{~h}$ in a 24 -well plate containing BGJb medium ( $2 \mathrm{mM}$ glutamine, $100 \mathrm{U} / \mathrm{mL}$ penicillin, $10 \mu \mathrm{M}$ streptomycin, $\left.37^{\circ} \mathrm{C}, 95 \% \mathrm{O}_{2}, 5 \% \mathrm{CO}_{2}\right)$. Each well $(200 \mu \mathrm{L})$ contained one gland, and the medium was replaced every $24 \mathrm{~h}$. The length of culture permitted the complete denervation of the gland (Parfitt et al., 1976).

\section{PINEALOCYTE DISPERSION}

Pinealocytes were cultured according to Ferreira et al. (2003). The glands were removed, cut into small pieces and dissociated with trypsin $\left(0.25 \%, 37^{\circ} \mathrm{C}, 15 \mathrm{~min}\right)$, followed by mechanical dispersion in the presence of $0.3 \%$ trypsin inhibitor in a solution: $\mathrm{NaCl} 120 \mathrm{mM}, \mathrm{KCl} 5 \mathrm{mM}, \mathrm{NaHCO}_{3} 25 \mathrm{mM}, \mathrm{KH}_{2} \mathrm{PO}_{4} 1.2 \mathrm{mM}$, and glucose $12 \mathrm{mM} ; 0.1 \% \mathrm{w} / \mathrm{v}$ bovine serum albumin. After centrifugation $\left(1000 \mathrm{~g}, 15 \mathrm{~min}, 25^{\circ} \mathrm{C}\right)$, the supernatants were resuspended in DMEM containing fetal bovine serum (10\% heat-inactivated) and penicillin $(100 \mathrm{U} / \mathrm{mL})$. Cell viability was estimated by Trypan blue exclusion. The pinealocytes were seeded in poly L-lysine-coated wells $\left(0.5\right.$ to $1 \times 10^{5}$ cells/well $)$ and maintained at $37^{\circ} \mathrm{C}, 5 \% \mathrm{CO}_{2}$ for $18 \mathrm{~h}$ before beginning the treatments.

\section{CELL VIABILITY TEST}

Cell viability was assessed using an MTT assay. Pinealocytes seeded at a density of $0.5 \times 10^{5}$ cells/well in 96 -well plates $(150 \mu \mathrm{L} /$ well $)$ were either treated or not treated with TNF $(80 \mu \mathrm{M})$ and MTT $(0.5 \mathrm{mg} / \mathrm{mL})$ for $4 \mathrm{~h}$ at $37^{\circ} \mathrm{C}$. NFKB-DNA binding and iNOS activity were inhibited by incubating the cells with PDTC $(25 \mu \mathrm{M})$ or $1400 \mathrm{~W}(1 \mu \mathrm{M})$, respectively. The formazan dye used was dissolved in dimethyl sulfoxide (DMSO 100\%). The plates were read in a microplate spectrophotometer (SpectraMAX 250, Molecular Devices, CA, USA) at $540 \mathrm{~nm}$. Cell viability was defined based on the percentage of optic density (OD) in each group as compared to the control group.

\section{IMMUNOHISTOCHEMISTRY}

For tissue preparation, the animals were deeply anesthetized by intramuscular injection of ketamine $(160 \mathrm{mg} / \mathrm{kg})$ plus xylazine $(40 \mathrm{mg} / \mathrm{kg})$ and perfused transcardially with $150 \mathrm{~mL}$ saline solution followed by $1000 \mathrm{~mL}$ of cold $4 \%$ paraformaldehyde fixative solution, $\mathrm{pH}$ 9.5. Each pineal gland was removed from the skull and cryoprotected in the same fixative solution plus $20 \%$ sucrose at $4^{\circ} \mathrm{C}$ for 3 days, followed by cryoprotection in PBS plus $30 \%$ sucrose at $4^{\circ} \mathrm{C}$. The pineal glands were embedded in Tissue-Tek freezing medium and stored at $-80^{\circ} \mathrm{C}$ for no longer than 2 weeks before sectioning with a cryostat $(30 \mu \mathrm{m})$. The immunohistochemistry assay was performed with free-floating sections incubated in the blocking solution (1\% BSA, $0.3 \%$ Triton X-100 in PBS) for $1 \mathrm{~h}$ at room temperature. The sections were then incubated with the primary antibodies under constant agitation for $48 \mathrm{~h}$ at $4^{\circ} \mathrm{C}$, rinsed with PBS (30 $\mathrm{min}$ ) and incubated with the secondary antibodies for $90 \mathrm{~min}$. After rinsing, the pineal sections were mounted on gelatin-coated slides. The negative staining controls omitted the primary antibodies. Under these conditions, staining was completely abolished.

The primary antibodies used were rabbit polyclonal anti-TNFR1 (1:100 dilution, ab19139, Abcam, Cambridge, MA, USA), mouse anti-ED-1 (1:100 dilution, ab31630, Abcam) and mouse monoclonal anti-GFAP Cy3-conjugated (1:2000 dilution, C9205, SIGMA). The concentrations of the antibodies were chosen according to a concentration-response curve for each antibody. In addition these antibodies were shown to be specific according to isotype or no immune species-specific serum controls for the respective cognate ligands (anti-TNF-R1, Harrison et al., 2007; anti-ED1, Machado et al., 2010; anti-GFAP, Nielsen et al., 
2009). The secondary antibodies used were anti-rabbit IgG FITCconjugated (1:200 dilution, F7512, SIGMA) and donkey antimouse IgG Cy3-conjugated (1:200 dilution, 715165150, Jackson ImmunoResearch, West Grove, PA, USA). Images were acquired using a confocal laser-scanning microscope (LSM 510, Zeiss, Baden-Wurttemberg, Germany). A HeNe 543/633 laser, an argon laser (excitation $488 \mathrm{~nm}$ ) and an enterprise laser (excitation $364 \mathrm{~nm}$ ) were used for Cy3 (560 nm emission), FITC (505 nm emission) and DAPI (435-485 $\mathrm{nm}$ emission) imaging, respectively.

\section{IMMUNOCYTOCHEMISTRY}

Immunocytochemistry was performed as described by da Silveira Cruz-Machado et al. (2010). Briefly, pinealocytes were cultivated on chamber slides ( 8 wells, $0.5 \times 10^{5}$ cells, $18 \mathrm{~h}$ ), fixed in $4 \%$ cold paraformaldehyde, permeabilized with $0.5 \%$ saponin and incubated with blocking buffer ( $1 \%$ BSA, $0.5 \%$ saponin, and $0.3 \mathrm{M}$ glycine in PBS) to avoid non-specific staining. The primary antibodies were diluted in PBS plus 1\% BSA and incubated for $18 \mathrm{~h}$ at $4^{\circ} \mathrm{C}$, rinsed with PBS and then incubated with fluorescent secondary antibodies for $1 \mathrm{~h}$ at room temperature. Next, the cell nuclei were stained with DAPI $(300 \mu \mathrm{M}, 5 \mathrm{~min})$ at room temperature. Controls were prepared by omitting the primary antibodies. Under this condition, the staining was completely abolished.

The primary antibodies used were rabbit polyclonal antiTNF-R1 (dilution 1:100, ab19139, Abcam), rabbit polyclonal anti-iNOS TRITC-conjugated (1:25, sc-651), anti-NFKBIA (1:50, sc371, Santa Cruz Biotechnology, Santa Cruz, CA, USA). Selectivity with specific peptide or isotype antibody was determined previously (Pavlovic et al., 1999). The secondary antibody used was anti-rabbit Texas Red (1:400, ab6793, Abcam). Images were acquired using confocal laser-scanning microscopy with different objectives on the Zeiss LSM 510 and a HeNe 543/633 laser for Texas Red/TRITC (650 and 560-615 nm emission, respectively). An enterprise laser equipped with an excitation filter of $364 \mathrm{~nm}$ and an emission filter of 435-485 nm was used for DAPI imaging. The fluorescence was quantified using ImageJ software (National Institutes of Health, USA).

\section{ELECTROMOBILITY SHIFT ASSAY Nuclear extracts}

The electromobility shift assay (EMSA) was performed according to Ferreira et al. (2005). The glands were first homogenized in a lysis buffer (10 mM HEPES, pH 7.5; $10 \mathrm{mM} \mathrm{KCl;} 0.1 \mathrm{mM}$ EDTA; 10\% (v/v) glycerol; $1 \mathrm{mM}$ DTT; $0.1 \mathrm{mM}$ PMSF) and, after adding NP-40 $(10 \%, v / v)$, the samples were vortexed for $10 \mathrm{~s}$ and centrifuged twice $\left(5000 \mathrm{~g}, 1 \mathrm{~min}, 4^{\circ} \mathrm{C}\right)$. The nuclear pellet was resuspended in a nuclear extraction buffer $(10 \mathrm{mM}$ HEPES, $500 \mathrm{mM} \mathrm{KCl,} 1 \mathrm{mM}$ EDTA, $1 \mathrm{mM}$ DTT, $0.1 \mathrm{mM}$ PMSF). The tubes were maintained on a rocking plate for $15 \mathrm{~min}\left(4^{\circ} \mathrm{C}\right)$ and then centrifuged $\left(20,000 \mathrm{~g}, 5 \mathrm{~min}, 4^{\circ} \mathrm{C}\right)$. The resulting supernatant (nuclear extract) was stored at $20^{\circ} \mathrm{C}$ for no longer than 1 week at $-20^{\circ} \mathrm{C}$. Prior the EMSA assay, the nuclear protein content was quantified at $280 \mathrm{~nm}$ using an ND-1000 spectrophotometer (Nanodrop, Wilmington, DE, USA).

\section{Gel shift assay}

An equal amount of protein of each sample $(6 \mu \mathrm{g})$ was incubated in a final volume of $15 \mu \mathrm{L}$ of a gel shift binding buffer
(mM: 10 Tris-HCl, pH 7.5; $1 \mathrm{MgCl}_{2} ; 50 \mathrm{NaCl} ; 0.5$ DTT; and $0.5 \mathrm{mM}$ EDTA; $4 \%$ glycerol; $1 \mu \mathrm{g}$ poly dI-dC) for $20 \mathrm{~min}$ at room temperature. Next, $\sim 40,000$ counts/min of double-stranded oligonucleotide probes containing the NFKB consensus sequence (5'AGTTGAGGGGACTTTCCCAGGC-3', Sinapse, São Paulo, São Paulo, Brazil) and labeled with $\gamma$-ATP-32P were added for $30 \mathrm{~min}$ at room temperature. The protein-DNA complexes were resolved in a non-denaturing 6\% polyacrylamide gel at $150 \mathrm{~V}$ for $1 \mathrm{~h}$ $30 \mathrm{~min}$ in TBE buffer (Tris-Borate/EDTA). After drying, the gel was exposed to XAR-5 Kodak film (Rochester, NY, USA) for $24-48 \mathrm{~h}$ at $-70^{\circ} \mathrm{C}$. Autoradiograms were scanned and analyzed densitometrically using ImageJ.

\section{Supershift assay}

Nuclear factor kappa B subunits were identified from a pool of four samples that were either stimulated or not stimulated with TNF (30-90 ng/mL, $5 \mathrm{~min}$ ) and incubated with $2 \mu \mathrm{g} / \mathrm{mL}$ of rabbit polyclonal affinity-purified antibodies for RelA, p50, p52, c-Rel, RelB, and Bcl3 from Santa Cruz Biotechnology (sc-109x, sc-114x, sc-298x, sc-70x, sc-226x, and sc-185x, respectively) for $45 \mathrm{~min}$ at room temperature before the addition of a ${ }^{32} \mathrm{P}-\mathrm{NFKB}$ probe. EMSA was carried out as described previously.

\section{TNF-INDUCED NITRIC OXIDE PRODUCTION IN ISOLATED PINEALOCYTES}

Nitric oxide production was detected in isolated pinealocytes using confocal laser-scanning microscopy and the intracellular indicator DAF-FM, which forms a fluorescent product after reacting with nitrite ions produced by the spontaneous oxidation of nitric oxide (Kojima et al., 1998).

Nitric oxide was detected in pinealocytes using the protocol described by Tamura et al. (2009). Pinealocytes were grown on glass coverslips $\left(200 \mu \mathrm{l} \mathrm{DMEM}, 37^{\circ} \mathrm{C}, 5 \% \mathrm{CO}_{2}\right)$ for $17 \mathrm{~h}$, and then incubated for $1 \mathrm{~h}$ in a saline solution: $\mathrm{NaCl} 150 \mathrm{mM}, \mathrm{KCl}$ $5 \mathrm{mM}, \mathrm{CaCl}_{2} 2 \mathrm{mM}, \mathrm{NaHCO}_{3} 15 \mathrm{mM}$, glucose $11 \mathrm{mM}$, and Larginine $0.1 \mathrm{mM}$ at $\mathrm{pH} 7.4$. Next, TNF $(80 \mathrm{ng} / \mathrm{mL})$, the antagonist of iNOS $(1400 \mathrm{~W}, 1 \mu \mathrm{M})$ or NFKB (PDTC, $25 \mu \mathrm{M})$ was added. TNF was incubated for $2 \mathrm{~h}$, PDTC and $1400 \mathrm{~W}$ were pre-incubated for 30 and $50 \mathrm{~min}$, respectively, before adding TNF. During the final $50 \mathrm{~min}$ after adding TNF, the cells were loaded in the dark with DAF-FM DA $(5 \mu \mathrm{M})$. The cells were then washed to remove excess probe and mounted on the stage of an inverted microscope equipped with a $40 \times$ oil-immersion objective.

Nitric oxide fluorescence was measured using an argon laser with excitation and emission wavelengths of $488 \mathrm{~nm}$ and 515-530, respectively, using a confocal laser-scanning microscope (ZEISS LSM 510). The fluorescence was quantified in three different fields per well, counting 7-10 cells/field. The cell perimeter was defined as the region of interest (ROI), and the increase in nitric oxide production was estimated as the percentage by which the nitric oxide donor, SNP (1 mM), increased intracellular nitric oxide.

\section{DATA ANALYSIS}

Data are presented as the mean \pm SEM. Gel shift assays were quantified using ImageJ. Statistical analyses were performed using ANOVA followed by the Newman-Keuls test. Values of $p<0.05$ were considered statistically significant. 


\section{RESULTS}

\section{TNF-R1 DISTRIBUTION IN THE DIFFERENT CELL TYPES IN PINEAL PARENCHYMA}

The rat pineal gland parenchyma is composed of different cell types, most of which are pinealocytes (approximately 90\%) and glial cells. First, we found that immune-like TNF-R1 was diffusely expressed in pineal gland sections, as shown in two different glands (Figures 1A,D). A diffuse image using the same antibody was observed in renal cell carcinoma cryosections (Harrison et al., 2007) and melanoma cell (Gray-Schopfer et al., 2007).

To identify the cell types, the astrocytes and microglia were identified with selective antibodies (GFAP for astrocytes and ED-1 for microglia). Astrocytes and microglia have specific localizations in the pineal gland. The immunoreactivity for GFAP was confined to the proximal region, specifically near the pineal stalk (Figure 1B), whereas the immunostaining for ED-1 revealed a diffuse pattern (Figure 1E). When the images of the two cell markers were merged with TNF-R1 immunostaining, co-localization with astrocytes (Figure 1C), and microglia (Figure 1F) was observed.

Analysis of the images at higher amplification shows that almost all astrocytes present immunoreactivity to TNF-R1; however, in the case of microglia, only some of the cells marked with ED-1 were immune-stained with antibodies against TNF-R1 (Figure 2).

\section{TNF-R1 IS EXPRESSED IN PINEALOCYTES}

To confirm the presence of TNF-R1 in pinealocytes, these cells were isolated and immunostained for TNF-R1 (Figure 3). We observed a dynamic variation in the immunoreactivity to TNF-R1, depending on the length of time that the pinealocytes were incubated with TNF ( $80 \mathrm{ng} / \mathrm{mL}$; Figure 3). The 30-min incubation period did not change the fluorescence intensity. However, incubation for 60 or 180 min resulted in $60 \%$ reduction in immunofluorescence intensity. The MTT viability test assured that the concentrations of TNF used did not lead to cell death. The MTT assay showed that cell death was observed only at much higher concentrations of TNF and that the other pharmacological tools used, such as PDTC and $1400 \mathrm{~W}$, also did not result in cell death. Therefore, we may conclude that the membrane detection of immunoreactivity for TNF-R1 is altered by long-lasting incubation with TNF. Thus, the downstream reactions triggered by activation of TNF-R1 were determined by incubating pinealocytes or pineal glands for less than $30 \mathrm{~min}$.

\section{TNF REDUCES NFKBIA}

One of the downstream events that transduce TNF-R1 signals is the nuclear translocation of NFKB dimers, which requires degradation of the inhibitory protein that sequesters these dimers in the cytoplasm. We observed a significant reduction of the

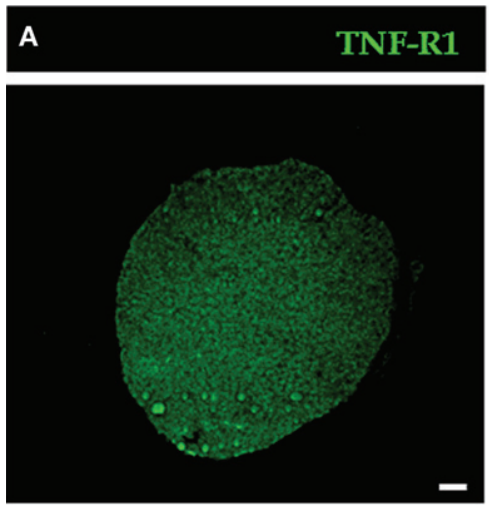

D

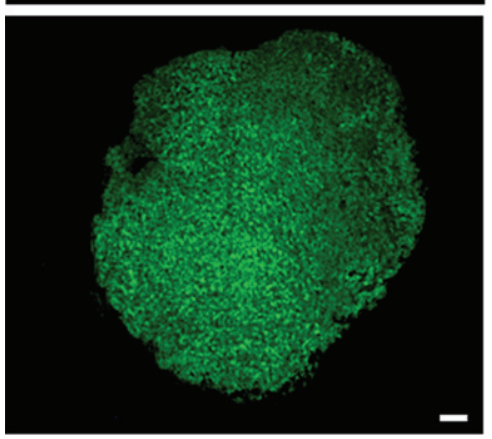

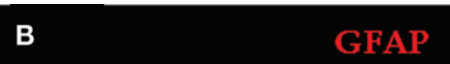
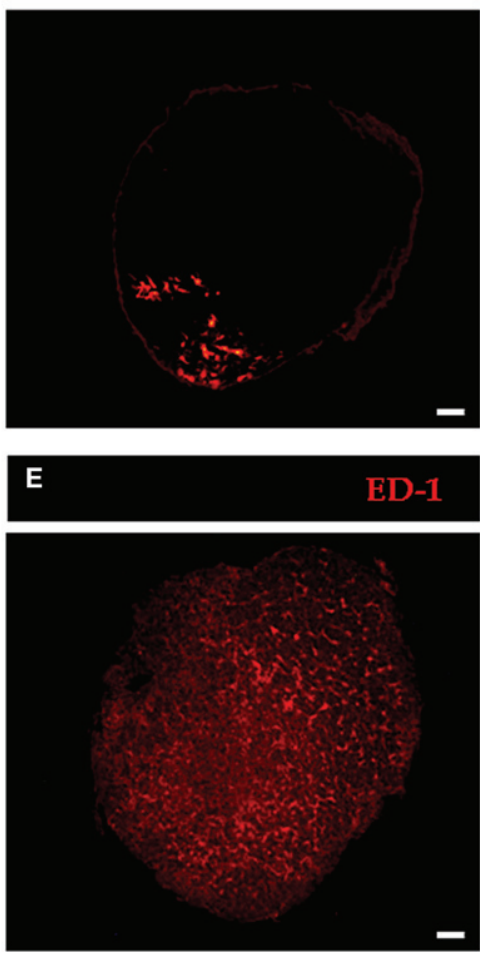
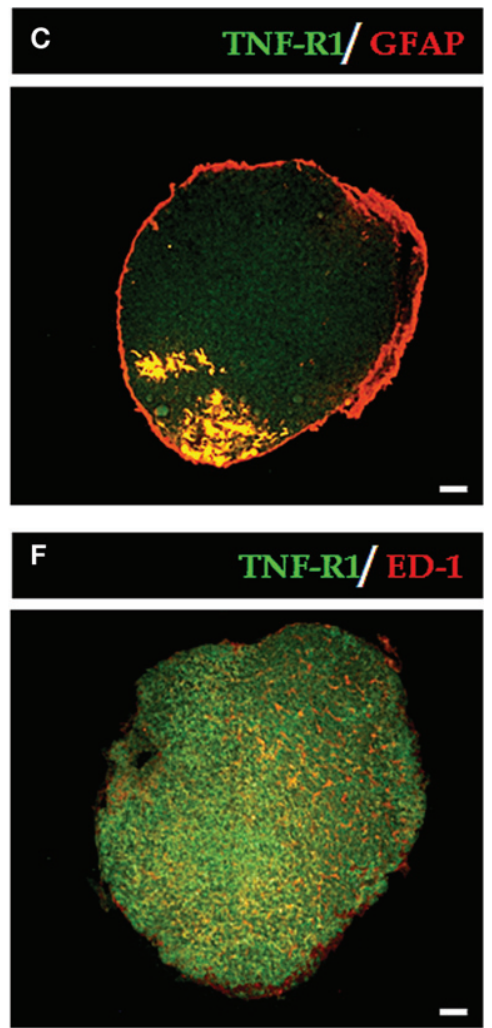

FIGURE 1 | Representative images of the expression of TNF-R1 in pineal gland sections. The immunopositive labeling of TNF-R1 throughout the pineal parenchyma is shown in green (A,D). Glial cells are stained in red: astrocytes [GFAP-labeled, (B)] and microglia [ED-1-labeled, (E)]. GFAP-positive cells are restricted to the proximal region near the pineal stalk (B), while ED-1-positive cells are dispersed in the pineal gland (E). In merged images, yellow indicates double labeling for TNF-R1 and GFAP (C) or ED-1-positive cells (F). Scale bar $=200 \mu \mathrm{m}$. 

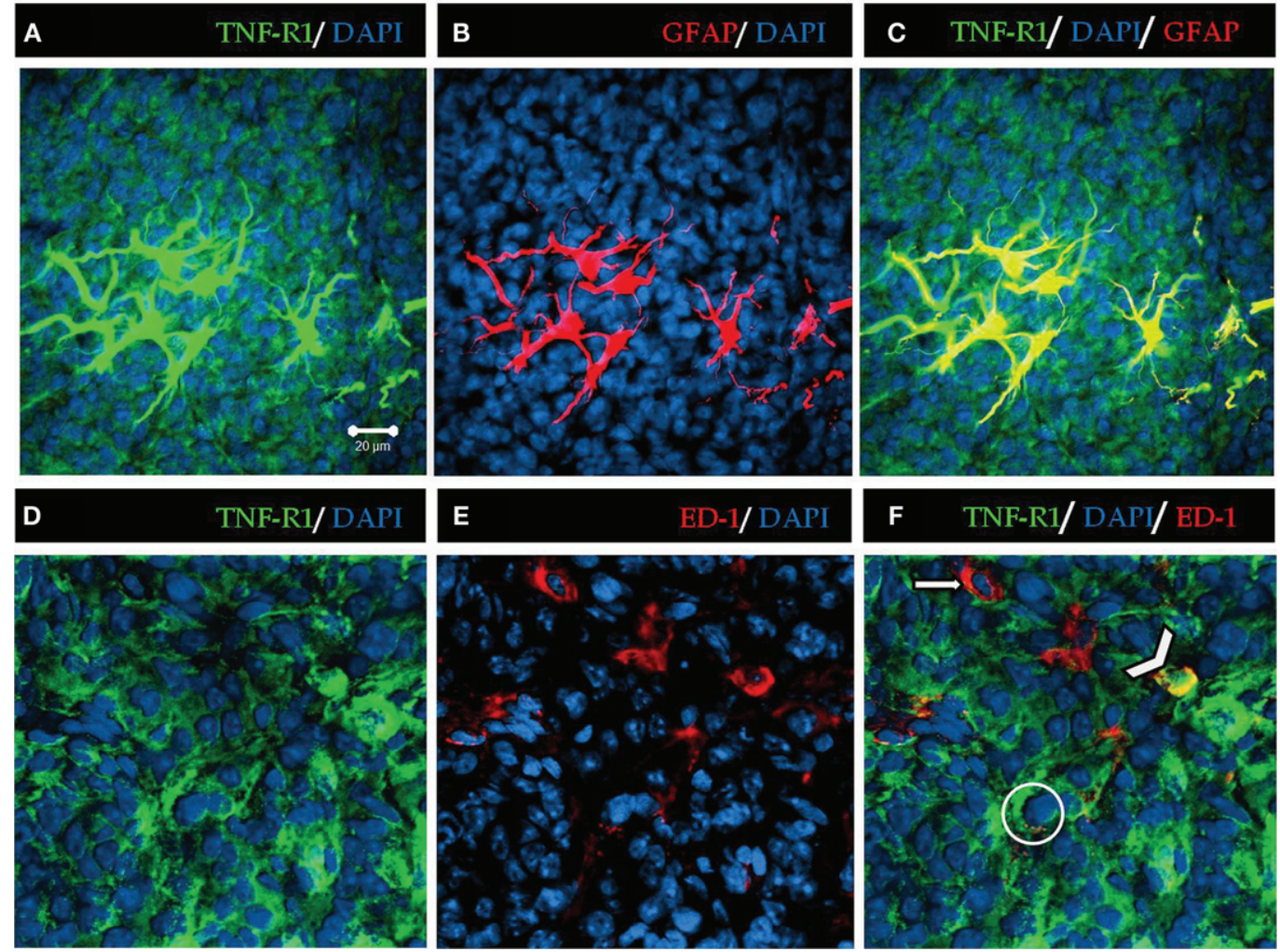

FIGURE 2 | High magnification of TNF-R1 expression in rat pineal sections. TNF-R1 is stained in green, showing positive immunoreactivity throughout the pineal parenchyma $(\mathbf{A}, \mathbf{C}, \mathbf{D}, \mathbf{F})$. The glial cells were stained in red with GFAP for astrocytes and ED-1 for microglia (B,E). Astrocytes (B) are confined to the proximal region of pineal gland. Microglia (E) present a diffuse pattern of distribution along the parenchyma. The blue staining represents nuclei stained by DAPI. The yellow merged images show positive co-localization of TNF-R1 in astrocytes (C) and microglia (F). The filled arrow (F) indicates that microglia (red) are negative for TNF-R1, and the arrowhead shows positive co-localization between microglia and TNF-R1 (yellow). The circle shows a pinealocyte expressing TNF-R1 (green). Scale bar $=20 \mu \mathrm{m}$ fluorescence intensity of the immunostaining for NFKBIA in isolated pinealocytes incubated for $10 \mathrm{~min}$ with TNF $(80 \mathrm{ng} / \mathrm{mL}$, Figure 4). Thus, TNF triggers the NFKB signaling throughout the degradation of NFKBIA.

\section{TNF INDUCES NUCLEAR TRANSLOCATION OF NFKB IN RAT PINEAL GLAND}

The effect of TNF on NFKB nuclear translocation was determined using EMSA in the cultured pineal glands stimulated with TNF (30 ng/mL) for 5-60 min. The NFKB nucleotide probe revealed two complexes ( $\mathrm{C} 1$ and $\mathrm{C} 2$ ), and TNF stimulation transiently increased the nuclear translocation of C1 (Figure 5). Significant increases in the translocation of the $\mathrm{C} 1$ subunit were observed at 5-min intervals.

The translocation of NFKB subunits was evaluated by incubating cultured pineal glands with TNF $(30 \mathrm{ng} / \mathrm{mL})$ for $5 \mathrm{~min}$. The supershift assay for DNA-protein complexes was conducted with specific antibodies for p50, RelA, p52, c-Rel, RelB, and Bcl-3. Only the $\mathrm{C} 1$ complex was supershifted; therefore, we could not identify C2 (Figure 6).

Nuclear extracts from non-stimulated glands were supershifted with p50 and RelA antibodies, but not with the other antibodies tested. p50 antibodies supershifted all complexes with $\mathrm{C} 1$, whereas RelA antibodies promoted a partial shift (Figure 6A).
Autoradiogram is shown in Figure 6B. It is interesting to note that we observed two supershifted bands for p50, but only one for RelA. On the other hand, p50 supershifted all of the C1 bands, but RelA antibodies only partially supershifted the $\mathrm{C} 1$ bands. Therefore, we conclude that in cultured pineal gland both p50/p50 and p50/RelA dimers are found in the nuclear extract.

The effect of TNF was evaluated by incubating glands for $5 \mathrm{~min}$ in various concentrations of TNF $(10,30,60$, and $90 \mathrm{ng} / \mathrm{mL})$. TNF induced the nuclear translocation of both dimers (p50/p50 and p50/RelA; Figure 7). Lower concentrations increased the nuclear translocation of p50/RelA, whereas higher concentrations were required to translocate both dimers.

\section{EXPRESSION OF INOS AND PRODUCTION OF NITRIC OXIDE}

The expression of iNOS was evaluated using immunofluorescence and pharmacological methods in isolated pinealocytes. Isolated pinealocytes were incubated for $120 \mathrm{~min}$ with TNF (30-90 ng/L). The cells were incubated sufficiently long to allow iNOS and nitric oxide to accumulate in amounts detectable by our techniques.

The expression of iNOS was TNF dose-dependent (Figures 8A,B) and was blocked by inhibition of NFKB with PDTC ( $25 \mu \mathrm{M}$, Figure $8 \mathrm{C})$. This de novo synthesized enzyme was responsible for the TNF-induced nitric oxide production, as it was blocked by a selective iNOS antagonist, $1400 \mathrm{~W}(1 \mu \mathrm{M}$, Figure 8D). 

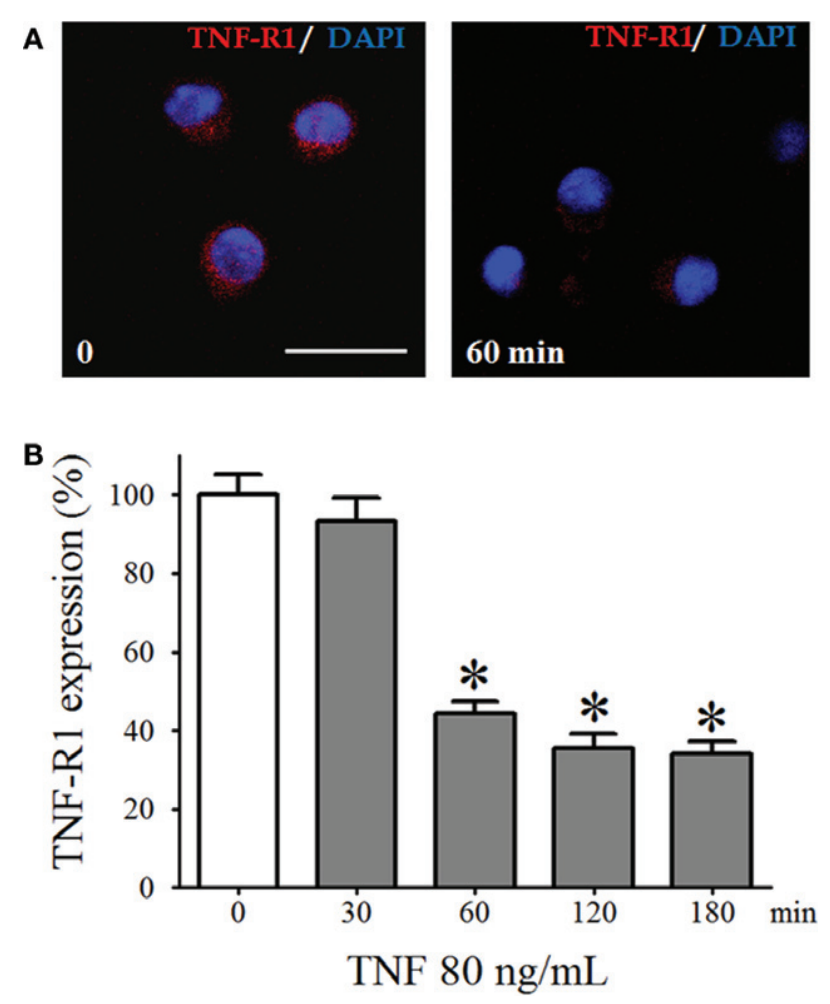

FIGURE 3 | The TNF-R1 expression in dispersed pinealocytes. (A) Representative immunocytochemistry images of cultured pinealocytes showing the constitutive expression of TNF-R1 (stained in red, left-hand side). Incubation with TNF $(80 \mathrm{ng} / \mathrm{mL})$ for 60 min reduces the detection of TNF-R1 (right-hand side). Blue staining represents fluorescent nuclei stained using DAPI. (B) Quantification of the fluorescence of pinealocytes stimulated (gray bars) or not stimulated (white bars) with TNF $(80 \mathrm{ng} / \mathrm{mL}$ ) for 30-180 min. Data are expressed as the mean \pm SEM; $n=4$ independent cultures. In each well, we counted 21 cells in three different, randomly chosen fields. ${ }^{*} p<0.05$ vs. no TNF. Scale bar $=20 \mu \mathrm{m}$.

\section{DISCUSSION}

The pineal gland, which is classically considered a neuro-humoral transducer of photic environmental information, is now considered an integral player in the immune response (Nelson et al., 2002; Skwarlo-Sonta et al., 2003; Markus et al., 2007). The indolamine melatonin has long been recognized as an immune-modulatory agent (Guerrero and Reiter, 2002; Hotchkiss and Nelson, 2002). However, only recently has the pineal gland per se been studied with regard to its role in the mounting of the inflammatory response (Markus et al., 2007). In the context of the immunepineal axis, the suppression of pineal melatonin synthesis favors the mounting of an inflammatory response. The presence of a receptor repertoire necessary for mediating the response to LPS and TNF (da Silveira Cruz-Machado et al., 2010) reinforces the idea that this gland participates in the regulation of the innate immune response. Here we studied the role of the pinealocytes and the mechanism triggered by the pro-inflammatory cytokine TNF as a first approach toward understanding the cellular mechanisms by which the pineal gland contributes to the innate immune response.

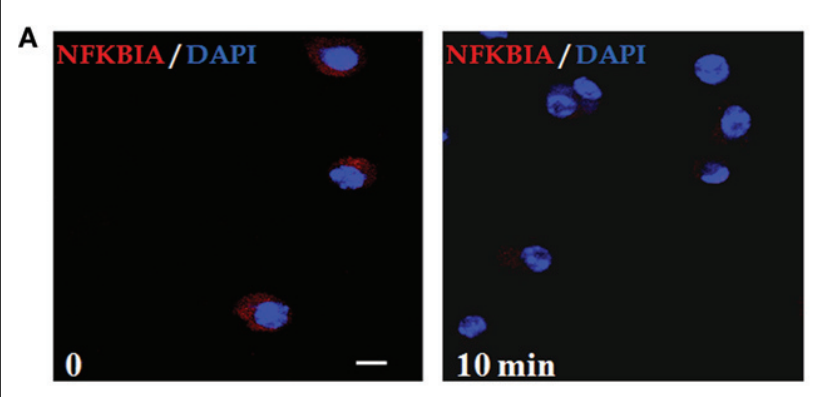

B

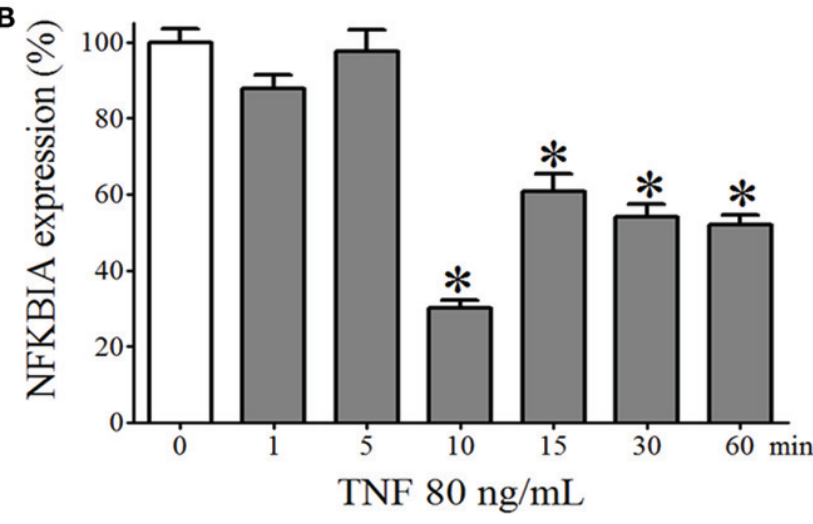

FIGURE 4 | NFKBIA expression in dispersed pinealocytes. (A)

Representative immunocytochemistry images demonstrating expression of NFKBIA (stained in red) in cultured pinealocytes in the absence (left-hand panel) or in the presence of TNF $(80 \mathrm{ng} / \mathrm{mL}$, for $10 \mathrm{~min}$; right-hand panel). Blue staining represents the fluorescent nuclei issued with DAPI. (B) Quantification of the fluorescence of pinealocytes stimulated (gray bars) or not stimulated (white bar) with TNF $(80 \mathrm{ng} / \mathrm{mL})$ for $1-60 \mathrm{~min}$. Data are shown as the mean \pm SEM; $n=3$ independent cultures. ${ }^{*} p<0.05$ vs. no TNF (white bar). Scale bar $=10 \mu \mathrm{m}$.

Tumor necrosis factor is a major pro-inflammatory mediator (Wajant et al., 2003) that signals through TNF-R1 and TNF-R2. TNF-R1 is expressed in many cells and tissues, whereas TNF-R2 is mostly found in cells of the immune system (Hehlgans and Männel, 2002). Soluble TNF has high affinity for TNF-R1 whereas membrane-bound TNF interacts with TNF-R2 (Grell et al., 1998; McCoy and Tansey, 2008). In the present study, we tested the effects of exogenous TNF; therefore, we focused our attention on TNFR1. First, we determined the cellular localization of TNF-R1 in the pineal gland. Then, after confirming its presence in the pinealocytes, we explored the signal transduction pathway that translates pinealocyte responses to TNF.

The three most important cells in the rodent pineal gland are astrocytes, microglia, and pinealocytes. Astrocytes, located in the stalk along the entrance site of the arteries and veins, are immunestained by GFAP (Luo et al., 1984; Zang et al., 1985; Schröder and Malhotra, 1987; Berger and Hediger, 2000; Jiang-Shieh et al., 2003), whereas several subtypes of cells that are labeled by specific antibodies and diffused alongside pinealocytes in the pineal parenchyma are collectively named microglia (Jiang-Shieh et al., 2003). Astrocytes and microglia were identified in the present work based on the immunoreactivity to GFAP and ED-1, respectively, whereas pinealocytes were isolated and cultured to confirm the 


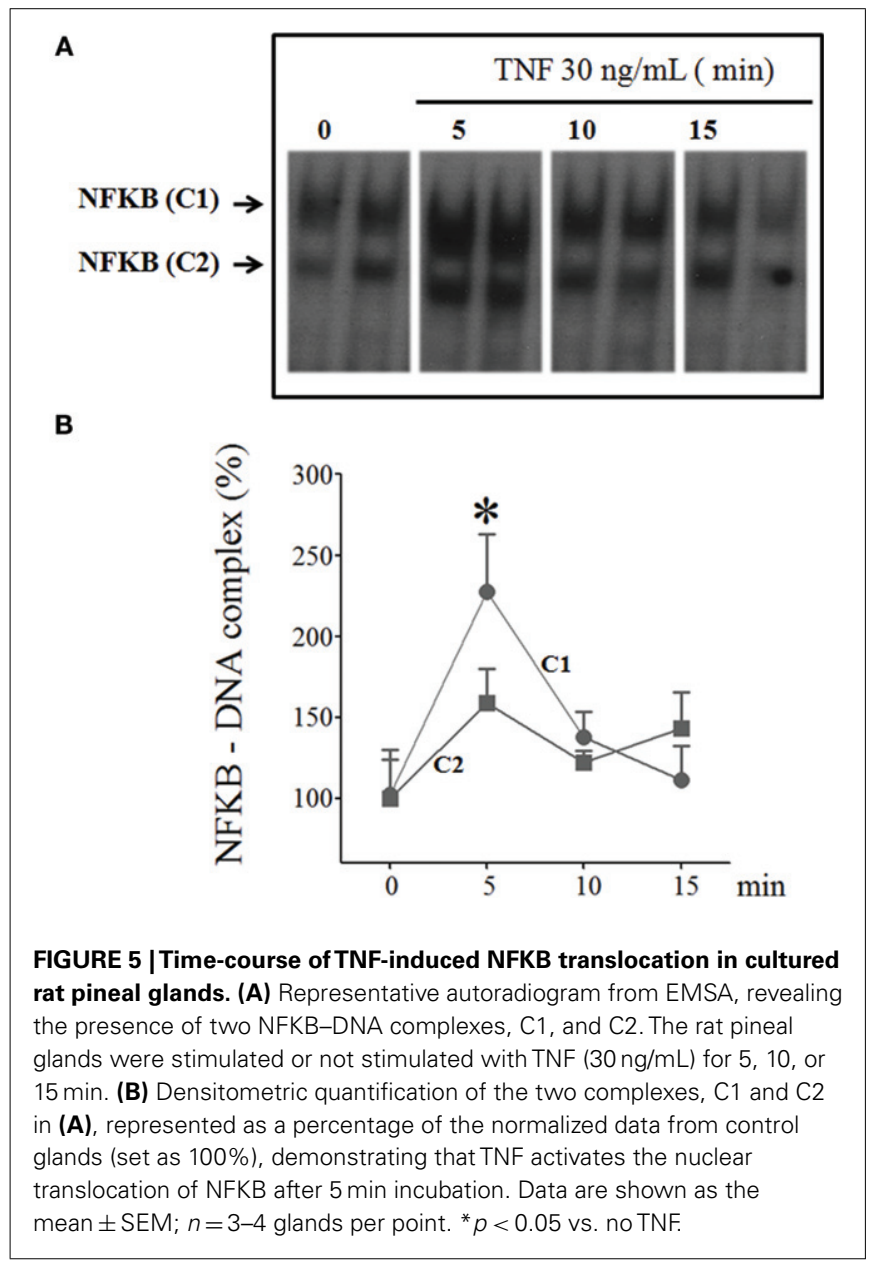

expression of TNF-R1 in these cells. All three cell types expressed TNF-R1 under resting conditions. Therefore, TNF signaling could integrate their responses. In this context, it is interesting to mention that the pineal gland could respond to circulating cytokines as well as TNF produced by the gland itself, as observed in cultured pineal glands stimulated with LPS (da Silveira Cruz-Machado et al., 2010).

The time-dependent reduction in the immunoreactivity of TNF-R1 when the isolated pinealocytes were incubated for 30-180 min suggests a reduction in the number of receptors available in the membrane. Although we did not pursue this subject, two mechanisms involved in reducing the number of TNF receptors available in the membrane are known (for reviews, see Higuchi and Aggarwal, 1994; Hehlgans and Männel, 2002). The first mechanism is related to receptor shedding, leading to a protein that binds circulating TNF. This mechanism is preferential for the reduction of TNF-R2. The second mechanism involves internalization, which is mandatory for TNF-induced apoptosis. Because activation of NFKB is independent of internalization, the time interval chosen for analyzing NFKB activation was shorter than that involved in receptor internalization.

The presence of TNF-R1 in pinealocytes strongly indicates that TNF directly affects melatonin production. We have observed previously that incubation of cultured rat pineal glands with TNF inhibits the noradrenaline-induced transcription of Aanat and the synthesis of $\mathrm{N}$-acetylserotonin, the immediate precursor of melatonin (Fernandes et al., 2006). These in vitro observations were corroborated by clinical data that show a suppression of the nocturnal melatonin surge in patients with high levels of circulating TNF, such as in the presence of sepsis (Mundigler et al., 2002), myocardial stroke (Domínguez-Rodríguez et al., 2002), and mastitis (Pontes et al., 2006). In addition, an analysis of the levels

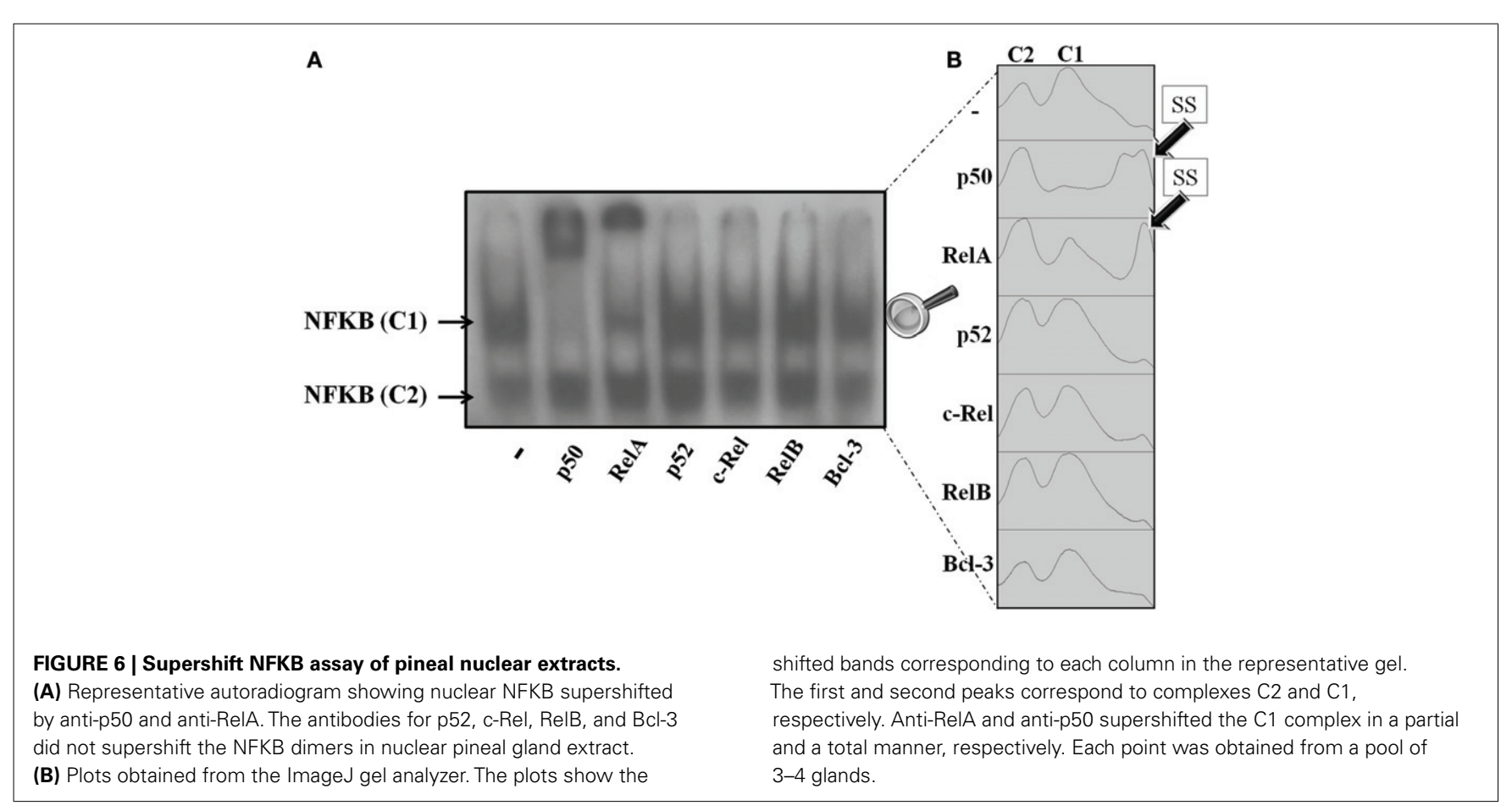




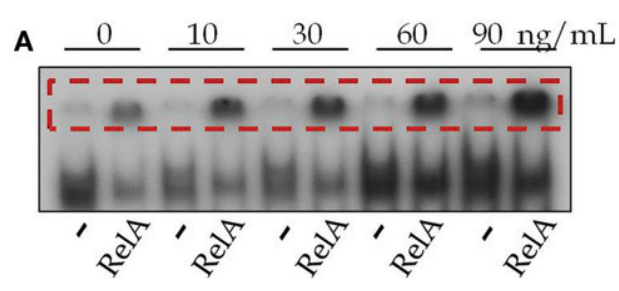

FIGURE 7 | Effects of TNF on the translocation of NFKB subunits to the nucleus. (A) Representative gel of anti-RelA-supershifted NFKB in glands stimulated or not stimulated with TNF

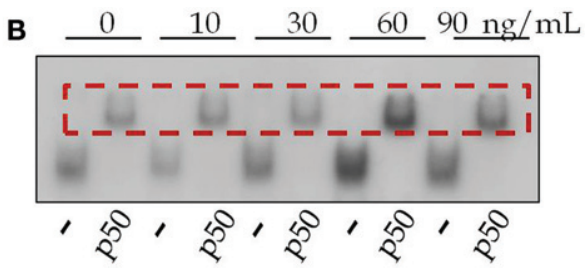

(10-90 ng/mL) for $5 \mathrm{~min}$. (B) Representative gel of anti-p50-supershifted NFKB in glands stimulated or not stimulated with TNF $(10-90 \mathrm{ng} / \mathrm{mL})$ for $5 \mathrm{~min}$.

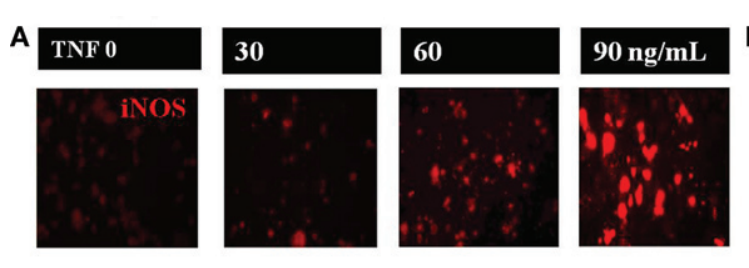

C

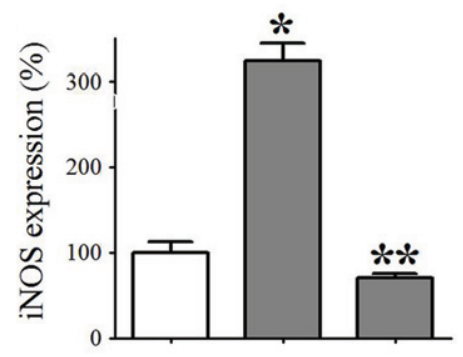

$\begin{array}{llll}\text { TNF }(80 \mathrm{ng} / \mathrm{mL}) & - & + & - \\ \operatorname{PDTC}(25 \mu \mathrm{M}) & - & - & +\end{array}$

FIGURE 8 | Tumor necrosis factor-induced iNOS expression and NO production in cultured pinealocytes. (A) Representative immunocytochemistry images showing staining against iNOS (red) in pinealocytes stimulated or not stimulated with TNF (30-90 ng/mL for $120 \mathrm{~min})$. (B) Quantification of the fluorescence intensity. (C) TNF (120 min)-induced iNOS expression is inhibited by PDTC (D).

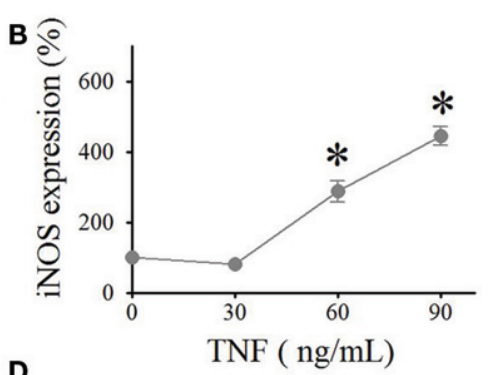

D

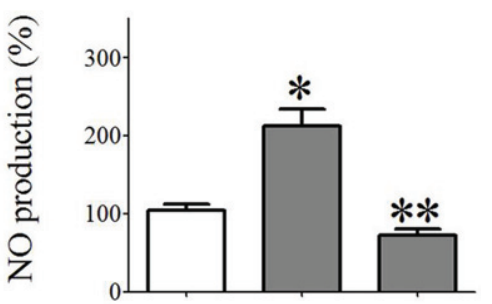

$\begin{array}{llll}\text { TNF }(80 \mathrm{ng} / \mathrm{mL}) & - & + & + \\ 1400 \mathrm{~W}(1 \mu \mathrm{M}) & - & - & +\end{array}$ PTC (25 MM). (D) TNF (120 min)-induced NO production in cultured pinealocytes is inhibited by $1400 \mathrm{~W}(1 \mu \mathrm{M})$. Data are expressed as the mean \pm SEM; $n=3$ independent experiments per parameter. ${ }^{*} p<0.05$ vs. no TNF (white bar); ${ }^{* *} p<0.05$ when comparing the groups stimulated with TNF in the presence or absence of $1400 \mathrm{~W}$ (C) or

of TNF and melatonin in mothers whose infants were delivered by cesarean section, a condition that induces an acute inflammatory response, has shown that the daily melatonin rhythm was recovered only in mothers with no circulating TNF (Pontes et al., 2007). Therefore, the hypothesis that activation of TNF-R1 triggers a transduction pathway that inhibits noradrenaline-induced melatonin production is supported by experimental and clinical findings.

Here, we show for the first time that activation of TNF$\mathrm{R} 1$ in pinealocytes reduces the expression of NFKBIA, allowing the migration of NFKB to the nuclei, as observed in immunecompetent cells and neurons (Lawrence, 2009). In rat pineal glands, TNF induced the translocation of two NFKB dimers: p50/p50 and p50/RelA. The major difference between these two dimers is that TAD is present only in p50/RelA (Hayden and
Ghosh, 2004). The binding of the dimer p50/p50 to the putative kappa B element in the promoter of Aanat (Markus et al., 2007) could explain the inhibition of its transcription, leading to the inhibition of the melatonin biosynthetic pathway (Fernandes et al., 2006). The dimer p50/RelA induces the transcription of a set of genes involved in the inflammatory response. Among several other proteins, iNOS is induced by p50/RelA in immunecompetent cells and in many other cell types, such as neurons (Bethea et al., 1998; Arias-Salvatierra et al., 2011), endothelial cells (Tamura et al., 2009), and muscle cells (Katsuyama and Hirata, 2001). We evaluated the expression of iNOS and the production of nitric oxide by isolated pinealocytes stimulated with TNF. Taking into account the pharmacological inhibition of iNOS expression and nitric oxide production by PDTC and $1400 \mathrm{~W}$, respectively, we concluded that the effect of TNF is mediated by NFKB. 


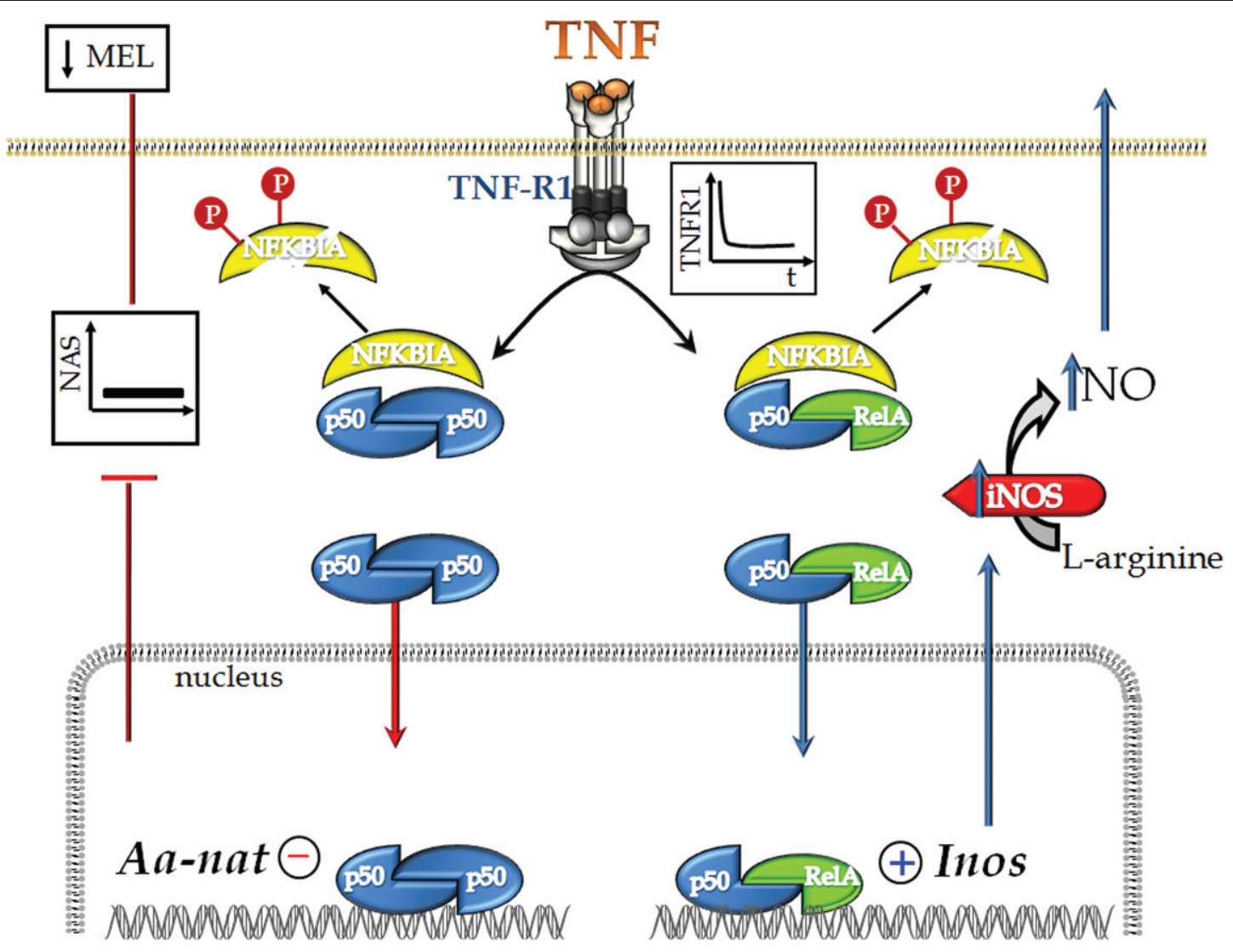

FIGURE 9 | Schematic representation of TNF's dual effect on rat pinealocytes. TNF stimulates TNF-R1, leading to internalization of the receptor and activation of the NFKB pathway. This activation is mediated by the degradation of NFKBIA and depends on its phosphorylation (Neumann and Naumann, 2007). Next, we observed the nuclear translocation of the p50/p50 and p50/RelA dimers. p50/p50 NFKB acts to inhibit gene transcription, whereas p50/RelA activates gene transcription. We have shown previously that TNF inhibits the transcription of Aanat, which encodes the key protein for melatonin synthesis (Fernandes et al., 2006). In fact, TNF inhibits melatonin synthesis. Here, we also show that the nuclear translocation of p50/RelA induces the transcription of iNOS, a hallmark enzyme of inflammatory responses. We suggest that the mechanism of action of TNF, as determined in the present paper, is the molecular basis for understanding the inhibition of melatonin synthesis that occurs at the beginning of an innate immune response.
Three different isoforms of nitric oxide synthase are expressed in the pineal gland; the endothelial and neuronal isoforms are constitutive and signal through cyclic GMP (Lin et al., 1994; Maronde et al., 1995; López-Figueroa and Møller, 1996a; Spessert et al., 1998; Jacobs et al., 1999), whereas the induced isoform is not present in basal conditions (Jacobs et al., 1999) and signals thorough the nuclear translocation of NFKB (this work; Kaur et al., 2007). The constitutive NOS are localized in blood vessels and near the stalk of the rat pineal gland (López-Figueroa and Møller, 1996b), whereas iNOS, as mentioned above, is found in the pinealocytes. In addition, the production of nitric oxide by activation of the constitutive NOS or stimulation of the gland with 8-Br-cyclic GMP (Maronde et al., 1995; Spessert et al., 1998) has no effect on the production of melatonin induced by adrenoceptor stimulation. On the other hand, production of nitric oxide by iNOS (this work) or the use of nitric oxide donors, such as sodium nitroprussiate and 3-morpholino-sydnonimine-1 (SIN-1), which releases a high concentration of nitric oxide, inhibits adrenergically induced melatonin production. Therefore, this could be a second mechanism involved in suppression of the nocturnal melatonin surge by TNF.

Together, these data clearly indicate that the activation of TNF$\mathrm{R} 1$ in pineal glands leads to the degradation of NFKBIA and the nuclear translocation of the dimers p50/p50 and p50/RelA (Figure 9). Although these dimers act through different mechanisms, we propose that both mechanisms could suppress adrenergically induced melatonin synthesis. The p50/p50 dimer directly inhibits Aanat gene transcription, whereas the p50/RelA dimer inhibits melatonin synthesis by inducing the production of $\mathrm{NO}$ in the pinealocytes.

In conclusion, this study provides mechanistic evidence for considering the pineal gland a key participant in the innate immune response. Understanding how the synthesis of melatonin is suppressed to permit the proper mounting of an inflammatory response is the initial step in evaluating why the daily rhythm of melatonin is not restored in some, but not all, chronic diseases. Considering the pinealocytes a target for cytokines improves our understanding of the role played by the pineal gland in organism defense. 


\section{AUTHOR CONTRIBUTION}

Claudia Emanuele Carvalho-Sousa: Acquisition and analysis/interpretation of data, writing the manuscript; Sanseray da Silveira Cruz-Machado: acquisition of data, writing the paper; Eduardo Koji Tamura: acquisition of data; Pedro A. C. M. Fernandes: acquisition of data, writing the manuscript; Luciana Pinato: acquisition of data; Sandra M. Muxel: acquisition of data; Erika Cecon: acquisition of data; Regina P. Markus: Concept/design, data interpretation, writing the manuscript. All authors approved submission of the manuscript to FCE.

\section{REFERENCES}

Arias-Salvatierra, D., Silbergeld, E. K., Acosta-Saavedra, L. C., and Calderon-Aranda, E. S. (2011). Role of nitric oxide produced by iNOS through NF-KB pathway in migration of cerebellar granule neurons induced by lipopolysaccharide. Cell. Signal. 23, 425-435.

Beni, S. M., Kohen, R., Reiter, R. J., Tan, D. X., and Shohami, E. (2003). Melatonin-induced neuroprotection after closed head injury is associated with increased brain antioxidants and attenuated latephase activation of NF- $\kappa B$ and AP-1. FASEB J. 1, 10-11.

Berger, U. V., and Hediger, M. A. (2000). Distribution of the glutamate transporters GLAST and GLT-1 in rat circumventricular organs, meninges, and dorsal root ganglia. J. Comp. Neurol. 421, 385-399.

Bethea, J. R., Castro, M., Keane, R. W., Lee, T. T., Dietrich, W. D., and Yezierski, R. P. (1998). Traumatic spinal cord injury induces nuclear factorkappaB activation. J. Neurosci. 18, 3251-3260.

Carrillo-Vico, A., Calvo, J. R., Abreu, P., Lardone, P. J., García-Mauriño, S., Reiter, R. J., and Guerrero, J. M. (2004). Evidence of melatonin synthesis by human lymphocytes and its physiological significance: possible role as intracrine, autocrine and/or paracrine substance. FASEB J. 18, 537-539.

Cecon, E., Fernandes, P. A., Pinato, L., Ferreira, Z. S., and Markus, R. P. (2010). Daily variation of constitutively activated nuclear factor kappa B (NFKB) in rat pineal gland. Chronobiol. Int. 27, 52-67.

da Silveira Cruz-Machado, S., CarvalhoSousa, C. E., Tamura, E. K., Pinato, L., Cecon, E., Fernandes, P. A., de Avellar, M. C., Ferreira, Z. S., and Markus, R. P. (2010). TLR4 and CD14 receptors expressed in rat pineal gland trigger NFKB pathway. J. Pineal Res. 49, 183-192.

Domínguez-Rodríguez, A., AbreuGonzález, P., García, M. J., Sanchez, J., Marrero, F., and de Armas-Trujillo,
D. (2002). Decreased nocturnal melatonin levels during acute myocardial infarction. J. Pineal Res. 33, 248-252.

Fernandes,P.A.C.M.,Cecon,E., Markus, R. P., and Ferreira, Z. S. (2006). Effect ofTNF-alphaonthemelatoninsynthetic pathway in the rat pineal gland: basis forafeedbackoftheimmuneresponse on circadian timing. J. Pineal Res. 41, 344-350.

Ferreira, Z. S., Cipolla-Neto, J., and Markus, R. P. (1994). Presence of P2- purinoceptors in the rat pineal gland. Br. J. Pharmacol. 112, 107-110.

Ferreira, Z. S., Fernandes, P. A. C. M., Duma, D., Assreuy, J., Avellar, M. C., and Markus, R. P. (2005). Corticosterone modulates noradrenaline-induced melatonin synthesis through inhibition of nuclear factor kappaB. J. Pineal Res. 38, 182-188.

Ferreira, Z. S., Garcia, C. R., Spray, D. C., and Markus, R. P. (2003). P2Y(1) receptor activation enhances the rate of rat pinealocyte-induced extracellular acidification via a calciumdependent mechanism. Pharmacology 69, 33-37.

Ghosh, S., and Hayden, M. S. (2008). New regulators of NF-kappaB in inflammation. Nat. Rev. Immunol. $11,837-848$.

Gilad, E., Wong, H. R., Zingarelli, B., Virág, L., O'Connor, M., Salzman, A. L., and Szabó, C. (1998). Melatonin inhibits expression of the inducible isoform of nitric oxide synthase in murine macrophages: role of inhibition of NFkappaB activation. FASEB J. 12, 685-693.

Gray-Schopfer, V. C., Karasarides, M., Hayward, R., and Marais, R. (2007). Tumor necrosis factor-alpha blocks apoptosis in melanoma cells when BRAF signaling is inhibited. Cancer Res. 67, 122-129.

Grell, M., Wajant, H., Zimmermann, G., and Scheurich, P. (1998). The type 1 receptor (CD120a) is the highaffinity receptor for soluble tumor necrosis factor. Proc. Natl. Acad. Sci. U.S.A. $95,570-575$.

\section{ACKNOWLEDGMENTS}

This work was supported by grants from the National Council for Research and Development $(\mathrm{CNPq})$ and the Foundation of Research of the Estado de São Paulo (FAPESP; thematic grant 07/07871-6). We thank Débora Aparecida Moura for technical assistance. Claudia Emanuele Carvalho-Sousa, Sanseray da Silveira Cruz-Machado and Erika Cecon are $\mathrm{PhD}$ fellows and Eduardo Koji Tamura is a post-doctoral fellow from FAPESP. Regina P. Markus is a senior fellow of CNPq.

Guerrero, J. M., and Reiter, R. J. (2002). Melatonin-immune system relationships. Curr. Top. Med. Chem. 2, 167-179.

Hardeland, R., and Fuhrberg, B. (1996). Ubiquitous melatonin - presence and effects in unicells, plants and animals. Trends Comp. Biochem. Physiol. 2, 25-45.

Harrison, M. L., Obermueller, E., Maisey, N. R., Hoare, S., Edmonds, K., Li, N. F., Chao, D., Hall, K., Lee, C. Timotheadou, E., Charles, K., Ahern, R., King, D. M., Eisen, T., Corringham, R., DeWitte, M., Balkwill, F., and Gore, M. (2007). Tumor necrosis factor alpha as a new target for renal cell carcinoma: two sequential phase II trials of infliximab at standard and high dose. J. Clin. Oncol. 29, 4542-4549.

Hayden, M. S., and Ghosh, S. (2004). Signaling to NF-kappaB. Genes Dev. 18, 2195-2224.

Hehlgans, T., and Männel, D. N. (2002). The TNF-TNF receptor system. Biol. Chem. 383, 1581-1585.

Higuchi, M., and Aggarwal, B. B. (1994). TNF induces internalization of the $\mathrm{p} 60$ receptor and shedding of the p80 receptor. J. Immunol. 152, 3550-3558.

Hotchkiss, A. K., and Nelson, R. J. (2002). Melatonin and immune function: hype or hypothesis? Crit. Rev. Immunol. 22, 351-371.

Huang, S. H., Cao, X. J., and Wei, W. (2008). Melatonin decreases TLR3-mediated inflammatory factor expression via inhibition of NFkappa B activation in respiratory syncytial virus-infected RAW264.7 macrophages. J. Pineal Res. 45, 93-100.

Jacobs, R. A., Schaad, N. C., Vanecek, J., Leaver, S., Aubry, J. M., Korf, H. W., Dahia, P. L., Chew, S. L., and Grossman, A. B. (1999). Pineal nitric oxide synthase, but not heme oxygenase, mRNA is suppressed by continuous exposure to light. Brain Res. Mol. Brain Res. 70, 264-272.

Jiang-Shieh, Y. F., Wu, C. H., and Chang, M. L. (2003). Regional heterogeneity in immunoreactive macrophages/microglia in the rat pineal gland. J. Pineal Res. 35, 45-53.

Katsuyama, K., and Hirata, Y. (2001). A pyrrolidinone derivative inhibits cytokine-induced iNOS expression and NF-kappaB activation by preventing phosphorylation and degradation of IkappaB-alpha. J. Biochem. 129, 585-591.

Kaur, C., Sivakumar, V., Lu, J., and Ling, E. A. (2007). Increased vascular permeability and nitric oxide production in response to hypoxia in the pineal gland. J. Pineal Res. 42, 338-349.

Kojima, H., Sakurai, K., Kikuchi, K., Kawahara, S., Kirino, Y., Nagoshi, H., Hirata, Y., and Nagano, T. (1998). Development of a fluorescent indicator for nitric oxide based on the fluorescein chromophore. Chem. Pharm. Bull. 46, 373-375.

Lawrence, T. (2009). The nuclear factor NF-kappaB pathway in inflammation. Cold Spring Harb. Perspect. Biol. 1, a001651.

Li, Z., Nickkholgh, A., Yi, X., Bruns, H., Gross, M. L., Hoffmann, K., Mohr, E., Zorn, M., Büchler, M. W., and Schemmer, P. (2009). Melatonin protects kidney grafts from ischemia/reperfusion injury through inhibition of NF-kB and apoptosis after experimental kidney transplantation. J. Pineal Res. 46, 365-372.

Lin, A. M., Schaad, N. C., Schulz, P. E., Coon, S. L., and Klein, D. C. (1994). Pineal nitric oxide synthase: characteristics, adrenergic regulation and function. Brain Res. 651, 160-168.

Lissoni, P., Barni, S., Tancini, G., Brivio, F., Tisi, E., Zubelewicz, B., and Braczkowski, R. (1994). Role of the pineal gland in the control of macrophage functions and its possible implication in cancer: a study of interactions between tumor necrosis factor-alpha and the pineal hormone melatonin. $J$. Biol. Regul. Homeost. Agents 8, 126-129. 
López-Figueroa, M. O., and Møller, M. (1996a). Nitric oxide synthase in the pineal gland. Histol. Histopathol. 11, 1089-1100.

López-Figueroa, M. O., and Møller, M. (1996b). Localization of NADPHdiaphorase in the rat pineal gland: an experimental enzyme histochemical study. J. Pineal Res. 20, 157-163.

Luo, Z. R., Schultz, R. L., Whitter, E. F., and Vollrath, L. (1984). The ultrastructure of the nerve fibers and pinealocytes in the rat pineal stalk. J. Pineal Res. 1, 323-327.

Machado, D. E., Berardo, P. T., Palmero, C. Y., and Nasciutti, L. E. (2010). Higher expression of vascular endothelial growth factor (VEGF) and its receptor VEGFR2 (Flk-1) and metalloproteinase- 9 (MMP-9) in a rata model of peritoneal endometriosis is similar to cancer diseases. J. Exp. Clin. Cancer Res. 29, 4.

Maestroni, G. J. (1998). The photoperiod transducer melatonin and the immune-hematopoietic system. J. Photochem. Photobiol. B Biol. 43, 186-192.

Markus, R. P., Ferreira, Z. S., Fernandes, P. A. C. M., and Cecon, E. (2007). The immune-pineal axis: a shuttle between endocrine and paracrine melatonin sources. Neuroimmunomodulation 14 126-133.

Maronde, E., Middendorff, R., Mayer, B., and Olcese, J. (1995). The effect of NO-donors in bovine and rat pineal cells: stimulation of cGMP and cGMP-independent inhibition of melatonin synthesis. J. Neuroendocrinol. 7, 207-214.

Martins, E. J., Ferreira, A. C., and Skorupa, A. L. (2004). Tryptophan consumption and indoleamines production by peritoneal cavity macrophages. J. Leukoc. Biol. 75, 1116-1121.

McCoy, M. K., and Tansey, M. G. (2008). TNF signaling inhibition in the CNS: implications for normal brain function and neurodegenerative disease. J. Neuroinflammation 5, 45.

Mundigler, G., Delle-Karth, G., Koreny, M., Zehetgruber, M., SteindlMunda, P., Marktl, W., Ferti, L., and Siostrzonek, P. (2002). Impaired circadian rhythm of melatonin secretion in sedated critically ill patients with severe sepsis. Crit. Care Med. 30, 536-540.

Nelson, R. J., and Demas, G. E. (1997). Role of melatonin in mediating seasonal energetic and immunologic adaptations. Brain Res. Bull. 44, 423-430.

Nelson, R. J., Demas, G. E., Klein, S. L., and Kriegsfeld, L. J. (2002). Seasonal Patterns of Stress, Immune Function, and Disease. Cambridge: Cambridge University Press.

Neumann, M., and Naumann, M. (2007). Beyond IkappaBs: alternative regulation of NF-kappaB activity. FASEB J. 21, 2642-2654.

Nielsen, M., Lambertsen, K. L., Clausen, B. H., Meldgaard, M., Diemer, N. H., Zimmer, J., and Finsen, B. (2009). Nuclear translocation of endonuclease $\mathrm{G}$ in degenerating neurons after permanent middle cerebral artery occlusion in mice. Exp. Brain Res. 194, 17-27.

O'Dea, E., and Hoffmann, A. (2009). NF-kB signaling. Wiley Interdiscip. Rev. Syst. Biol. Med. 1, 107-115.

O'Neill, L. A., and Kaltschmidt, C. (1997). NF-kappa B: a crucial transcription factor for glial and neuronal cell function. Trends Neurosci. 20, 252-258.

Parfitt, A., Weller, J. L., and Klein, D. C. (1976). Beta-adrenergic blockers decrease adrenergically stimulated $\mathrm{n}$-acetyltransferase activity in pineal glands in organ culture. Neuropharmacology 15, 353-358.

Pavlovic, D., Chen, M. C., Bouwens, L., Eizirik, D. L., and Pipeleers, D. (1999). Contribution of ductal cells to cytokine responses by human pancreatic islets. Diabetes 48 , 29-33.

Pontes, G. N., Cardoso, E. C., CarneiroSampaio, M. M., and Markus, R. P. (2006). Injury switches melatonin production from endocrine (pineal) to paracrine (phagocytes) melatonin in human colostrum and colostrum phagocytes. J. Pineal Res. 41, 136-141.

Pontes, G. N., Cardoso, E. C., CarneiroSampaio, M. M., and Markus, R. P. (2007). Pineal melatonin and the innate immune response: the TNF alpha increase after cesarean sections suppress nocturnal melatonin production. J. Pineal Res. 43 , 365-371.

Schröder, H., and Malhotra, S. K. (1987). Characterization of rodent pineal astrocytes by immunofluorescence microscopy using a monoclonal antibody (J1-31). Cell Tissue Res. 248, 607-610.

Skwarlo-Sonta, K., Majewski, P., Markowska, M., Oblap, R., and Olszanska, B. (2003). Bidirectional communication between the pineal gland and the immune system. Can. J. Physiol. Pharmacol. 81, 342-349.

Spessert, R., Layes, E., Hill, G., and Vollrath, L. (1998). Nitric oxide is formed in a subpopulation of rat pineal cells and acts as an intercellular messenger. Neuroendocrinology 68, 57-63.

Tamura, E. K., Cecon., E., Arantes, A. W., Silva, C. L., and Markus, R. P. (2009). Melatonin inhibits LPS-induced NO production in rat endothelial cells. $J$. Pineal Res. 46, 268-274.

Tamura, E. K., Fernandes, P. A., Marçola, M., da Silveira Cruz-Machado, S., and Markus, R. P. (2010). LongLasting priming of endothelial cells by plasma melatonin levels. PLoS ONE 5, e13958. doi: 10.1371/journal.pone. 0013958

Tan, D. X., Hardeland, R., Manchester, L. C., Paredes, S. D., Korkmaz, A.
Sainz, R. M., Mayo, J. C., FuentesBroto, L., and Reiter, R. J. (2010). The changing biological roles of melatonin during evolution: from an antioxidant to signals of darkness, sexual selection and fitness. Biol. Rev. Camb. Philos. Soc. 85, 607-623.

Wajant, H., Pfizenmaier, K., and Scheurich, P. (2003). Tumor necrosis factor signaling. Cell Death Differ. 10, 45-65.

Zang, X., Nilaver, G., Stein, B. M. Fetell, M. R., and Duffy, P. E. (1985). Immunocytochemistry of pineal astrocytes: species differences and functional implications. J. Neuropathol. Exp. Neurol. 44, 486-495.

Conflict of Interest Statement: The authors declare that the research was conducted in the absence of any commercial or financial relationships that could be construed as a potential conflict of interest.

Received: 06 December 2010; accepted: 27 April 2011; published online: 13 May 2011.

Citation: Carvalho-Sousa CE, da Silveira Cruz-Machado S, Tamura EK, Fernandes PACM, Pinato L, Muxel SM, Cecon $E$ and Markus RP (2011) Molecular basis for defining the pineal gland and pinealocytes as targets for tumor necrosis factor. Front. Endocrin. 2:10. doi: 10.3389/fendo.2011.00010

This article was submitted to Frontiers in Cellular Endocrinology, a specialty of Frontiers in Endocrinology.

Copyright (c) 2011 Carvalho-Sousa, da Silveira Cruz-Machado, Tamura, Fernandes, Pinato, Muxel, Cecon and Markus. This is an open-access article subject to a non-exclusive license between the authors and Frontiers Media $S A$, which permits use, distribution and reproduction in other forums, provided the original authors and source are credited and other Frontiers conditions are complied with. 